\title{
Evidence based medicine: ideology, hegemony, statistical gaze and beyond
}

\author{
Harindra Karunatilake ${ }^{1}$
}

Since its beginnings with Socrates, philosophy has often involved the project of questioning the accepted knowledge of the day. It allows better understanding of the current knowledge and paves the way for people to consider alternative narratives of the concept of knowledge. Evidence based medicine (EBM) paradigm provides an excellent textbook example to employ philosophical teaching to analyse the process, content and principles of EBM with an object to understand the perceptions that EBM has conclusive answers to all the questions.

This is not a critique of evidence-based medicine or we do not suggest anything beyond EBM. The objective of this three part article series is to have a philosophical discourse in the simplest form using the EBM paradigm. This has been done before [1,2,3]. Most of the philosophical discourses of EBM has been done in the context of criticizing its principles. Our discourse includes only the essence of the theories of Hegel, Kant and Marx and work of post modernists Derrida and Foucault. We confess at the outset that our discourse is a physician's overview of philosophy underpinning EBM and not one of a reader of philosophy attempting to read EBM.

We hope this discourse would stimulate the initiated physician to venture beyond the matrix and explore EBM paradigm more meaningfully.

One of the standard definitions of EBM reads as follows: the conscientious, explicit, and judicious use of current best evidence in making decisions about the care of individual patients. Evidence-based medicine is designed to help clinicians read the medical literature more effectively, and to encourage clinical management decisions based on randomized clinical trials and other well-designed studies rather than on "opinion, unsystematic clinical experience, or pathophysiologic rationale" [4].

Ceylon Medical Journal 2021; 66: 5-7

DOI: http://doi.org/10.4038/cmj.v66i1.9352

${ }^{1}$ National Hospital of Sri Lanka

Correspondence: HK, e-mail: <sunrat21@gmail.com>. Received 05 December 2020 and revised version 10 February 2021 accepted 20 March 2021.

This is an open-access article distributed under the terms of the Creative Commons Attribution License, which permits unrestricted use, distribution, and reproduction in any medium, provided the original author and source are credited.
Since the inception, EBM has had its own share of opponents. EBM has a ring of obviousness to it and anything else, especially opinion-based health care practice is discussed with a negative connotation. The EBM paradigm admits pathophysiologic reasoning or clinical experience as evidence only when information from more highly ranked methods is not available.

There has been several detailed extensive and comprehensive critique of EBM [5]. Some have gone a step further and suggested a new doctrine beyond evidencebased medicine to overcome the short falls of the EBM [6].

\section{Ideology and EBM}

The concept of ideology plays an important part in contemporary social and political thinking. In general, it is the relationship between what men think and how their societies operate. Ideology is a set of shared concepts, beliefs and attitudes of a group or an individual. However in true Marxist sense an ideology is a similar set of ideas and ideals that propagate, promote and persists a dominant political doctrine [7]. For example, that "the liberal capitalism is the only future in current political environment and the only possible change is 'some tinkering of tax structure' with an increase in minimal wage” is an ideology that propagates the existing majority political structure. However an ideology does not have to be essentially true or palatable to everyone.

In same vein we can consider that "evidence-based medicine is the only effective way of practicing medicine with best outcomes and facts and figures derived from randomized controlled trials (RCTs) and 'meta-analyses' are the best form of evidence" is an ideology which promotes and propagates EBM. As in the previous example this ideology needs not be true or accurate in any sense. Nevertheless this ideology promotes EBM. 
How cannot all that be accurate? The systematic reviews and meta-analyses concentrate on randomized trials to assess the effectiveness of interventions. However there are many other questions in health apart from “effectiveness of intervention”. For example patients' values and physicians' experience. EBM states that they "integrate research evidence with clinical expertise and patient values" in their conclusions but how it is done is not clearly stated. Patients' values, perception of good health and physician-patient interaction are deemed unimportant in the EBM paradigm. Most of these ideas are non-quantitative and they are dismissed as evidence and not represented in EBM. The current hierarchy of EBM tends to define qualitative research as of lower evidentiary status, despite its appropriateness to many research questions.

Secondly acceptable research for EBM must be based on randomised controlled trials design which constitute only $2 \%$ of the literature. Rest of the $98 \%$ is deemed scientifically redundant by EBM [5]. So the ideology "evidence-based medicine is the only effective way of practicing medicine with best outcome and facts and figures derived from randomized controlled trials (RCTs) and 'meta-analysis' are the best form of evidence" is not $100 \%$ accurate.

The strongest driving force of that ideology is the claim "the EBM is the only effective way of practicing medicine with best outcome". There has not been a single study that has compared the outcome between opinion based practice and evidence based practice. It is ironic to find there is no convincing evidence to date to say that doctors practicing EBM provide better health care than those who do not. Evidence based medicine is not evidence based. However the ideology behind EBM suggests it is "self-evident" that practicing EBM results in better outcomes and it is "common sense" to accept that over opinion based practice.

This ideology works to incite, reinforce and control, how we practice medicine excluding other forms of knowledge. Clinical decisions that are not based on results obtained from the meta-analyses of RCTs are called intuitive, guesswork practice, mere opinion or assumptions and discarded by the EBM paradigm. Hence some opponents of EBM have gone to an extent of calling this ideology a Fascist structure [2].

On the other hand, opinion-based practice of medicine relies on clinical experience of a physician. When dealing with individual patients, doctors rely on their own clinical authority (experience, clinical knowledge) to decide what is best for the patient, presumably independent of what the 'evidence' tells them to do. That can be intuitive, nonscientific and at times idiosyncratic. It sounds autocratic, authoritative and one might find it difficult to challenge that practice. Challenging a senior clinician's treatment strategy could be viewed as challenging medical professional hierarchy. It could even be considered as challenging a generation or a revolt against an accepted norm.

When it comes to actual clinical utility of EBM, it is totally different to opinion-based practice. In this context EBM can be considered democratic because it allows discussion. A clinical decision of a senior physician can be challenged by a junior colleague based on evidence. There is already an established hierarchy of evidence and one could know where you stand with your opinion.

\section{Hegemony and EBM}

Hegemony is a "theory" that has been conceived, articulated, and developed by Antonio Gramsci who is being recognized as the greatest Marxist thinker since Karl Marx. Hegemony is political or cultural dominance or authority over others. According to Gramsci "the ruling classes promote and propagate their own values, ideas, beliefs and norms in such a way that the subordinate class identifies it as for their own good and they consent for the rule of the dominant ideology" [8]. He called it cultural hegemony. Important difference is this is not done by coercion. It is done by using state apparatus like media, religion, law and education. Hegemony is this consenting of the people to the dominant ruling ideology without coercion considering it as "common sense". This helps to maintain the state and the economy without revolt. How does this apply to EBM paradigm?

In a very short period of time, EBM has become widespread and in fact has become the only accepted way to practice medicine in most people's eyes. Not only the healthcare practice, teaching at medical schools and medical research too are dominated by EBM. Given the unreasonably high status attributed to EBM, it is considered problematic if you practice medicine contrary to EBM. Some practitioners and hospitals request detailed justification documented when you sway from EBM recommendations, especially for legal purposes. So EBM has become the natural way to practice medicine. One would argue that EBM is reasonably called a hegemony when all that is considered.

Increasing number of evidence-based medical journals, exclusive use of only evidence-based medicine in formulating guidelines and teaching evidence-based medicine as the 'naturalized' practice in medical schools are the few reasons that explain why EBM has become a hegemony.

In court of law, in medical indemnity cases when medical practices are contested EBM practice is considered as the comparator or the gold standard. EBM has become the most influential doctrine in medicine and forms the basis for making healthcare policy to practice medicine at the clinics. We dare not question EBM and its conclusions and even if we do, we do on terms that allowed by EBM itself. The advocates of EBM do not believe that EBM's 
lack of evidence (evidence-based medicine is not evidence based) should even pose a problem. They go so far as to suggest that this 'evidence' being so 'self-evident', it seems, that to question it would be foolish. We consent to the rule of EBM without any form of coercion as we were pre-conditioned.

In the next article of this three part series we would explore how Kantian ethics would influence the EBM paradigm and utilize post-modernist Derida's concept of deconstruction to further analyze it.

\section{Conflicts of interest}

There are no conflicts of interest.

\section{References}

1. Devisch I, Murray SJ. Deconstructing 'evidence-based' medical practice. Journal of Evaluation in Clinical Practice 2009; 15: 950-4.
2. Holmes D, Murray SJ, Perron A, Rail G. Deconstructing the evidence-based discourse in health sciences: truth, power and fascism. Int J Evid Based Health 2006; 4: 180-6.

3. Tonelli MR. Philosophical limitations of evidence based medicine. Acad Med. 1998; 73: 1234-40.

4. The Evidence-Based Medicine Working Group. Evidencebased medicine: a new approach to teaching the practice of medicine. JAMA 1992; 268: 2420-5.

5. Cohen AM, Zoe-Stavri P, Hersh WR. A categorization and analysis of the criticisms of Evidence-Based Medicine. International Journal of Medical Informatics 2004; 73: 35-43.

6. Henry SG, Zaner RM, Dittus RS, Moving Beyond Evidence-Based Medicine. Acad Med. 2007; 82: 292-7.

7. Drucker HM. Marx's Concept of Ideology. Philosophy 1972; 47: 180: 152-61.

8. Bates TR. Gramsci and the Theory of Hegemony. Journal of the History of Ideas 1975: 36(2) 351-66. 